\title{
NARRATIVAS DE GENJI NO PERÍODO MEIJI (1868-1912) \\ - DO PONTO DE VISTA DA RELAÇÃO LITERATURA E ESTADO $^{1}$
}

\section{Rei Kufukihara ${ }^{2}$}

Resumo: Apresentamos três trabalhos de literatos da Era Meiji relativos à obra Narrativas de Genji do séc. XI. O primeiro, de um jovem diplomata que se estabeleceu na Inglaterra com o objetivo de com ela evidenciar a elevada cultura japonesa naquele país. O segundo, um romance de Ichiyo Higuchi que sofreu influências de Genji no que diz respeito a uma jovem que é vendida pelos seus pais para prostituição. O nome de sua obra diz respeito à impossibilidade de o Estado japonês lidar com as pessoas comuns e as crianças. E o último, um poema de Akiko Yosano que contesta a guerra Russo-Japonesa. Enquanto Akiko é receptiva aos diversos sentimentos humanos presentes em Genji, julgando-os mais importantes do que o país, e critica o Imperador Meiji, como seu comandante supremo, Ichiyo não se lamenta por tais contradições, mas foca na experiência e no pensamento da personagem principal perante a vida. Para ambas, Narrativas de Genji representa um trabalho encorajador para o reconhecimento da realidade, deixando de ser simplesmente uma obra literária clássica.

Palavras-chave: Narrativas de Genji; Era Meiji; propriedades da literatura clássica; a naçãoestado japonesa; reconhecimento da realidade.

Abstract: We pick up three people's works from Meiji era concerned with The Tale of Genji, written in the $11^{\text {th }}$ century. The first one, a translation of The Tale of Genji done by a young diplomat established in the UK in order to show to the great powers of that country how much the Japanese culture was a high-level one. The next one, a novel by Ichiyo Higuchi, influenced by The Tale of Genji, is about a young girl who is sold by her own parents to prostitution. The novel's name refers to the impossibility of the Japanese nation-state to deal with common people and children. The last one, a poem by Akiko Yosano cries out against the Russo-Japanese war. The reason why is that Akiko accepted various human feelings that appear in The Tale of Genji:

1 O presente trabalho foi publicado na Revista Setsurin 65. Associação de Literatura Nacional da Aichi Prefectural University, março de 2017 (ISSN 0586-8017) tendo por base a palestra de 19/10/17 no Simpósio Internacional "Natsume Sôseki, época, sociedade e obras literárias", no CEJAP - USP, como Professora Visitante de 2016 enviada pela Fundação Japão para o Programa de Pós-Graduação em Língua, Literatura e Cultura Japonesa da USP quando ministrei a disciplina Narrativas de Genjiestrutura e principais temas. Agradeço profundamente aos organizadores e colaboradores do evento em que explanei também sobre o autor, mas que não se encontra inserido neste texto.

2 Professora Doutora do Departamento de Cultura Japonesa, Aichi Prefectural University; r.kufuki@ gmail.com. 
delight, sadness and heartbreaking. For Akiko, such human feelings are more important than the war by the nation-state. So she criticizes even the Emperor Meiji as the top of the command hierarchy. Ichiyo does not cry against the contradiction of Japanese state and makes it clearly by writing the heroin's behavior and mentality in a lively way. For these two women, Ichiyo and Akiko, The Tale of Genji is not only the classical literature, but works as the encouraging recognition of reality.

Keywords: The Tale of Genji; Meiji era; a faculty of classical literature; Japanese nation-state; a recognition of reality.

\section{Introdução}

Teceremos reflexões sobre determinadas circunstâncias em torno da obra Narrativas de Genji no período Meiji (1868-1912) e seus significados na Literatura e na sociedade japonesas, a partir do ponto de vista da "Literatura e Estado". Há

Primeiramente, deter-nos-emos, em especial, em três fatos relacionados à "Literatura e Estado" conforme assinalados abaixo:

(1) 1882 (Meiji 15) primeira tradução de Genji Monogatari (Narrativas de Genji) no mundo, em inglês.

(2) 1895 (Meiji 28) publicação de Takekurabe (Comparando estaturas) da escritora Higuchi Ichiyô.

(3) 1904 (Meiji 37) início da disciplina acerca de Narrativas de Genji ministrada pela escritora Yosano Akiko.

O item (1) diz respeito à primeira tradução de Narrativas de Genji em inglês publicada em 1882. Essa tradução anunciava ao poderoso mundo europeu e estadunidense que o Japão era dotado de uma elevada cultura enquanto Estado moderno. O item (2) diz respeito à publicação de Comparando estaturas em 1895, pela escritora Higuchi Ichiyô (1872-1896) que criou uma obra nova a partir de uma leitura atenta de Narrativas de Genji, fazendo uso da psicologia das personagens e dos desenvolvimentos dessa narrativa. Contrapondo-se a (1), a autora foca na vida do povo japonês, sobretudo na protagonista que ocupa o estrato mais baixo da sociedade da época e, descrevendo as figuras humanas que estão ao seu redor, revela como é a vida do povo e a situação dessa sociedade num Estado moderno japonês. Por fim, o item (3) trata do início da Disciplina sobre Narrativas de Genji ministrada pela escritora Yosano Akiko (1878-1942 ) em 1904, o que irá frutificar na versão em língua japonesa moderna de Narrativas de Genji e contribuir significativamente para a sua disseminação entre o público em geral. É digno de nota que nesse mesmo ano, Akiko publica o poema que se opunha à guerra RussoJaponesa intitulada Kimi shinitamô koto nakare (Tu não precisas morrer). Midaregami 
(Cabelos revoltos), sua coletânea de poemas, enaltece a "vida" e o "sexo com amor" e esse seu espírito ia de encontro ao "Estado" enquanto cerceador da natureza do ser humano e por fim, transforma-se numa voz crítica e direta ao Imperador.

Essas três obras ligadas às Narrativas de Genji possuem, cada qual, características e função distintas, mas são fatos interligados entre si e que como uma engrenagem, projetam de modo profundo e perspicaz o período denominado Meiji e suas transformações. Isto é, (1) refere-se à ação de um jovem diplomata do Estado no início do referido período, ardente na missão de disseminar o elevado valor da cultura japonesa no exterior. Quanto ao (2), diz respeito à uma jovem protagonista destinada a se tornar cortesã na zona de prazeres de Yoshiwara, em Tokyo, revelando o sistema do Estado que é constituído por uma lógica masculina. Em relação ao (3) sobre o poema de Akiko contra a guerra, trata-se de um protesto em relação aos homens que também se mantém presos ao sistema do Estado sem condições de se rebelarem por terem suas vidas ameaçadas. É possível, assim, traçar o mapeamento de um apelo ao mundo no período Meiji. No início do período, pela a posição de um jovem diplomata; nos meados, uma descrição do sistema estatal para as mulheres que, como classe mais frágil, não possuía a menor ideia sobre os direitos humanos e no final dele, uma figura feminina enfrentando, por meio da literatura, o Estado japonês que usa os homens para a guerra sem que eles tenham outra alternativa. Nesse esquema, é possível ver que o ponto de vista da Literatura avança do nível do Estado para o nível do povo e que eles são difundidos pela posição ocupada pela mulher.

\section{Narrativas de Genji na Era Meiji - Visão por meio da cronologia.}

Entre 1867 (Ano 3 da Era Keiô), quando o Imperador Meiji sobe ao trono, até a derrota do Japão na Segunda Guerra Mundial, há três aspectos dignos de nota em relação à "Literatura e Estado", os quais estão assinalados com um $\square$ abaixo:

\section{Cronologia}

1867 (Keiô 3) Subida ao trono do Imperador Meiji.

1868 (Meiji 1) Novo Governo; anúncio a todos os países estrangeiros sobre a Restauração do Governo Imperial.

1876 (Meiji 9) Kondô Yoshiki (1801-1880): Cerne de Narrativas de Genji - visão histórica imperial pela educação feminina.

(1) 1882 (Meiji 15) $\begin{aligned} & \text { Suematsu Kenchô (1855-1920) outorga a primeira tradução } \\ & \text { para o inglês. } 17 \text { volumes }\end{aligned}$ 
1889 (Meiji 22) Promulgação da Constituição do Grande Império do Japão

1890 (Meiji 23) Promulgação das Diretrizes Imperiais para a Educação.

Mikami Sanji (1865-1939) e Takatsu Kuwasaburô (18641921): História da Literatura Japonesa (visão histórica de um império).

Revista Fujo (Senhoras). (Narrativas de Genji é uma obra centrada no Imperador)

1894 (Meiji 27) Guerra Sino-Japonesa

(2) 1895 (Meiji 28) Higuchi Ichiyô: Comparando estaturas e Nigorie (Desenho turvo)

1897 (Meiji 29) morte de Higuchi Ichiyô

1900 (Meiji 33) Fujioka Sakutarô (1870-1910) inicia a Disciplina História Geral da Literatura Nacional - Volume Corte de Heian (Universidade Imperial de Tokyo)

Ł1904 (Meiji 37) Guerra Russo-Japonesa (setembro: Tu não precisas morrer)

\begin{tabular}{|l|} 
(3) Yosano Akiko inicia a Disciplina Narrativas de Genji (Associação \\
Shinshi)
\end{tabular}

1905 (Meiji 38) Natsume Sôseki publica Eu sou um gato

(3) 1907 (Meiji 40) Yosano Akiko inicia a Disciplina Narrativas de Genji (em sua residência)

1908 (Meiji 41) Sôseki publica Sanshirô

1911 (Meiji 44) Julgamento do Atentado ao Imperador - condenação à morte de Kôtoku Shûsui (1871-1911) e outros 
1912 (Meiji 45) Akiko publica Nova tradução de Narrativas de Genji (até 1913)

1916 (Taishô 5) Morte de Sôseki (dezembro, 50 anos de idade)

1925 (Taishô14) Arthur Waley (1889-1966) traduz Narrativas de Genji para o inglês

Promulgação da Lei de Preservação da Paz e Segurança

1936 (Taishô 11) Tentativa frustrada de Golpe de Estado por jovens oficiais em 26 de fevereiro de 1936.

(3)1938 (Shôwa13) $\quad$ Akiko publica Novíssima tradução de Narrativas de Genji outra tradução em língua japonesa moderna (até1939)

1941 (Shôwa 16) Deflagração da Guerra do Oceano Pacífico

1943 (Shôwa 18) Tanizaki Jun'ichirô (1886-1965) começa a publicar As irmãs Makioka na revista Chûô Kôron e fica proibido de continuar a publicação

1945 (Shôwa 20) Japão, derrota na Guerra.

3. A primeira tradução de Narrativas de Genji foi feita para o inglês em 1882 (Meiji 15) por um japonês em Londres.

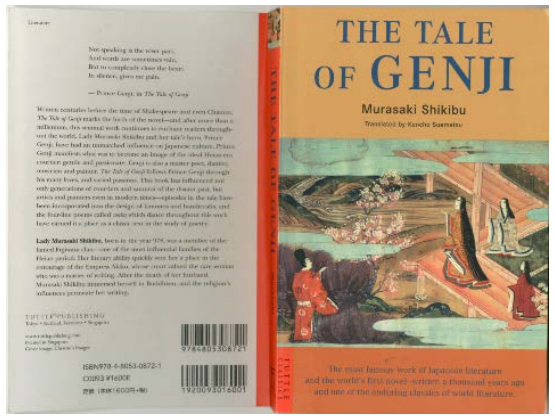

Figura A - Capa da tradução em inglês Suematsu Kenchô pela Tuttle Publishing, 1974. 


\section{(1) Quem foi Suematsu Kenchô}

O tradutor Suematsu objetivava anunciar a cultura japonesa no exterior. Suematsu foi descoberto por Itô Hirofumi (1841-1909), o primeiro Premiê japonês, e tornou-se um dos sustentáculos do primeiro ao quarto Gabinete de Itô, principalmente como Ministro de Estado e contraiu matrimônio com sua segunda filha. A partir de seu histórico resumido, veremos quais foram as circunstâncias para a tradução de Narrativas de Genji por Suematsu.

$\mathrm{O}$ motivo principal que o levou à tradução de Narrativas de Genji foi o reconhecimento de sua competência com a língua inglesa como jornalista, e de ter sido enviado a Londres como diplomata em 1878. Suematsu ingressou na Universidade de Cambridge em 1880, formou-se Bacharel em Direito em 1884 e nesse ínterim outorga a tradução para o inglês de Narrativas de Genji. Três anos antes, ele apresentou Registro do ressurgimento de Yoshitsune 3 , tese que defendia que "Yoshitsune = Genghis Khan" e, entre outras coisas, traduziu poemas ingleses para o japonês, retornando ao Japão em 1886 durante o primeiro mandato do Gabinete de Itô.

Dessa forma, o primeiro objetivo de Suematsu era obter o título de bacharel em Direito pela Universidade de Cambridge, o que serviu de alicerce para atuar como diplomata ou funcionário do alto escalão do governo, mas ele também possuía grande interesse pela literatura e pela cultura tradicional do Japão e ao voltar para o Japão, também contribuiu para a melhoria das artes dramáticas juntamente com Fukuchi Gen'ichirô (1841-1906) e Toyama Masakazu (1848-1900). E pelo desejo de Itô Hirofumi também tornou realidade a participação do Imperador Meiji nas apresentações do teatro Cabúqui (tenran kabuki).

A partir desses fatos é possível observar que suas atuações no âmbito literário e cultural eram surpreendentes, mas depois de se tornar Mestre em Direito em 1888 e casar-se com Seiko, a segunda filha de Itô Hiromi em 1889, assume uma posição importante como oficial do governo. Tudo vai de vento em popa na sua vida pública e privada e como mostraremos a seguir, é o sustentáculo de Itô como funcionário e como ministro até o quarto mandato de Itô.

Em 1892, assume como Secretário do Departamento de Direito na formação do segundo mandato do Premiê Itô, em seguida, torna-se membro do Câmara dos Nobres, e no terceiro e quarto mandato de Itô atua como Ministro. (No terceiro, como Ministro das Comunicações e no quarto, como Ministro do Interior, respectivamente em 1898 e 1900)

Entretanto, além de seu trabalho como funcionário do governo ou como Ministro, algo digno de nota é que em 1904 quando eclode a guerra Russo-Japonesa, ele promove uma atividade de divulgação na Inglaterra a mando de Itô para formar uma opinião pública favorável ao Japão. E, depois da vitória japonesa na guerra contra a Rússia,

3 N.T.: Diz respeito a Minamotono Yoshitsune (1159-1189), general que levou o clã Taira à derrocada em 1185, na batalha decisiva na baía de Dan'noura, Província de Yamaguchi. 
retorna ao Japão em 1906 (Meiji 39). Tendo reconhecido seu mérito no exterior torna-se Conselheiro dos Assuntos Privativos e no ano seguinte, torna-se membro da Associação dos Escolásticos do Império.

Desde que retornou ao Japão até a sua morte em 1920, publicou vários livros de história relacionados à Restauração Meiji e de suas pesquisas sobre Direito Romano.

(2) Objetivo e significado da primeira tradução para o inglês de Narrativas de Genji por Suematsu Kenchô

O primeiro e maior objetivo da tradução inglesa de Narrativas de Genji era dar a conhecer no exterior que o Japão possuía uma cultura elevada desde os tempos antigos, e a tradução coincide com o período do Salão Rokumei ${ }^{4}$.

$\mathrm{O}$ chamado período do Salão Rokumei diz respeito à segunda metade dos anos 10 de Meiji ou seja, por volta de 1882 a 1887, em que se procurou ampliar o europeísmo, por meio de festas e bailes realizados no Salão Rokumei com altos funcionário do Governo e os nobres, da parte do Japão, e as comitivas diplomáticas vindas da Europa e Estados Unidos. Esses eventos tinham o objetivo de avançar as negociações de modo favorável ao Japão para a mudança no acordo injusto firmado em 1882 (Meiji 15). É possível observar a ligação desse fato com a tradução inglesa de Narrativas de Genji em 1882. Enquanto no Japão eram realizadas as atividades no Salão Rokumei, no exterior, Suematsu Kenchô apresenta a obra como expressão da elevada cultura japonesa.

Como mencionado, Suematsu vai à Inglaterra para realizar atividades de propaganda sob ordem do então Primeiro Ministro Itô Hirofumi, quando eclode a guerra Russo-Japonesa, de modo que a tradução inglesa de Genji também se fundamentava numa base política.

(3) A primeira tradução inglesa de Narrativas de Genji foi outorgada à Familia Tokugawa e não ao Imperador (KAWAKATSU, 2008).

(1) A restauração do poder Imperial do governo de Meiji tinha por ideal a obra Man'yôshû (Miríade de folhas) e não Narrativas de Genji.

Narrativas de Genji não foi outorgada ao Imperador porque apesar de ser uma obra que manifesta o teor elevado da cultura palaciana, o Período Heian (séc. X-XII) foi

4 N.T.: O Salão Rokumei foi uma proposta do político Inoue Kaoru (1836-1915) que atuou no mundo financeiro e diplomático do governo Meiji. Foi projetado por Josiah Conder (1852-1920) arquiteto inglês que foi ao Japão a convite do governo japonês em 1877 para formar arquitetos japoneses e contribuiu para o desenvolvimento da arquitetura moderna japonesa com projetos importantes do início de Meiji. Em estilo ocidental de dois pavimentos, o salão foi edificado no distrito de Chiyoda, região central de Tokyo e tornou-se símbolo do enaltecimento da cultura ocidental-europeia. Após críticas em relação à essa exacerbação, tornou-se um edifício da aristocracia japonesa a partir de 1889. 
a época do governo de Tutores e Conselheiros da família Fujiwara e não foi governada pelos Imperadores ou Príncipes Regentes. O Imperador Meiji trocou o chapéu e as vestes formais aristocratas pela farda militar, "resgatando" um passado localizado no período mitológico dos imperadores anterior ao Período Nara (séc. VIII-X), de modo que a cultura palaciana refinada de Narrativas de Genji não condizia com a imagem de Estado do povo.

Por isso, o Governo Meiji elevou Miríade de folhas à expressão da imagem do Imperador que reunia e governava diretamente o povo japonês moderno. Nesse sentido, essa obra literária foi importante e ideal, atuando como elo inquestionável com o Imperador, enquanto dirigente do Estado japonês (SHINADA, 2001).

\section{(2) O duplo sentido de Narrativas de Genji no Governo Meiji.}

Sem sombra de dúvidas, Narrativas de Genji é uma obra digna de orgulho perante o mundo, mas ao mesmo tempo, descreve a sociedade aristocrática "devassa" das relações amorosas e adúlteras entre homens e mulheres. Consequentemente, seu apelo para o exterior como orgulho da cultura japonesa permanece, mas, internamente, distancia-se do ideal almejado pelo Estado Meiji. Assim, dentro do país, o que se almejava não era uma obra palaciana, e sim uma literatura enquanto "expressão de uma emoção comum, autêntica e direta" (SHINADA, 2001). Por meio de poemas assim, que poderiam ligar o povo e o Imperador, a obra Miríade de folhas foi alçada à categoria de literatura pela qual o povo poderia ter orgulho.

A esse respeito, a "Primeira Sessão Poética" do ano realizada atualmente no Palácio Imperial é uma forma de consolidar a harmonia do Imperador e seu povo por meio dos poemas e segue o caminho traçado pelo Estado Meiji.

Por esses motivos, a tradução para o inglês de Narrativas de Genji feita por Suematsu Kenchô enquanto diplomata não foi divulgado pelo governo Meiji. Pelo seu elevado teor literário, essa obra foi escolhida como objeto de propaganda no exterior sobre a existência de uma cultura elevada no Japão, mas não seria exagero afirmar que se tratava de uma obra que se gostaria de manter oculta dentro do Japão.

\section{Higuchi Ichiyô - surgimento da obra Comparando estaturas e seu significado}

- A sucessão verdadeira de Narrativas de Genji e a criação de uma nova literatura. 


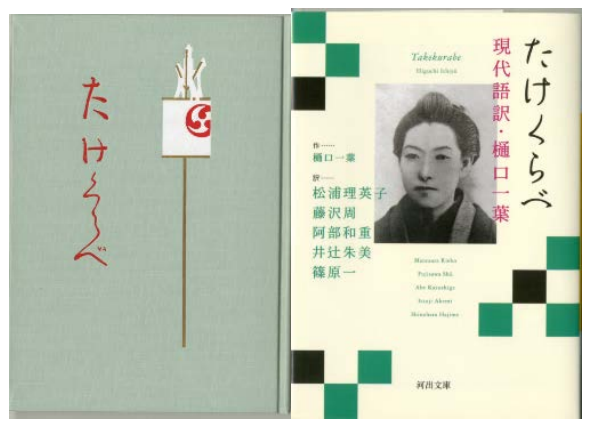

Figura B - Capas de Comparando estaturas, dois exemplos ${ }^{5}$

Comecemos pelo enredo da obra.

O cenário é a cidade baixa de Tóquio do início de Meiji. A protagonista é Midori, uma jovem bela e dinâmica de 14 anos. Ela acalenta sentimentos ternos por Shinjo, de 15 anos, filho do monge de um templo. As crianças das redondezas se confrontam divididas em dois grupos, e Midori pertence a um deles e Shinjo ao outro.

$\mathrm{Na}$ noite do festival de verão de agosto, um dos meninos mais levados do grupo de Shinjo ofende Midori em público, além de arremessar uma sandália cheia de barro em sua testa. Shinjo, que não estava no festival, fica condoído ao saber do fato e, a partir do dia seguinte ao acontecido, Midori deixa de ser a menina alegre de sempre, fechando-se dentro de casa. Mesmo com a visita de Shôta de 13 anos e que lhe era mais próximo, ela continua sob o edredom assumindo uma atitude histérica.

No período de chuva intermitente de final do outono, Midori faz um penteado takashimada usado pelas moças que alcançam a maioridade (no Japão, alcançada aos 20 anos), e é elogiada por todos por sua beleza, mas ela se fecha dizendo: "não quero virar adulta. Ser adulto é algo desagradável". Na realidade, Midori é a filha de um casal que trabalha e mora num estabelecimento chamado Casa Daikokue, na zona de prazeres em Yoshiwara, Tóquio. A primeira menstruação da menina sinalizava a hora de se tornar uma cortesã na mesma casa.

Shinjo, por sua vez, vai para a escola de monges fora da cidade. Na manhã de sua partida, uma flor artificial de narciso é colocada no portão da Casa Daikoku na qual vive Midori, e apesar de ela não ter condições de saber que a flor fora enviada por Shinjo, toma-a nas mãos com um sentimento inexplicável de saudade.

5 À esquerda, reimpressão da primeira edição de Takekurabe da Coletânea de Obras Completas de Obras Modernas de 1976, e, à direita, a tradução em língua moderna com o retrato de Ichiyô em edição de bolso pela Editora Kawai, 2004. 


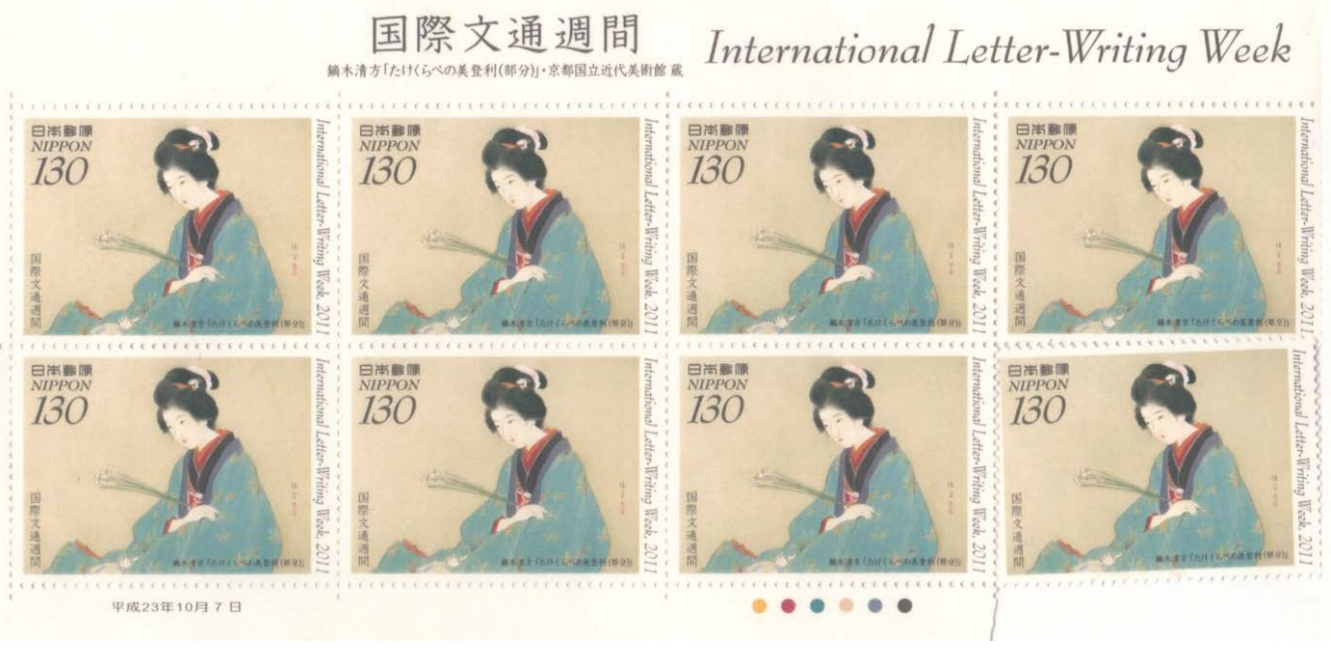

Figura C - Selo da personagem Midori em Comparando estaturas.

Desenho de Kaburagi Kiyokata, acervo do Museu Nacional de Arte Moderna de Kyoto.

(1) A peculiaridade e o significado desse romance residem na criação de uma obra nova mesmo que baseada numa leitura minuciosa de Narrativas de Genji.

Como característica gerais, pode-se apontar o mundo aristocrático do Período Heian retratado nos costumes do povo da época Meiji. Mais concretamente, a cena da disputa dos carros de boi da dama Rokujô no Miyasundokoro na Festa de Aoi, em Narrativas de Genji, é utilizada na obra de Ichiyô na briga da Festa de Verão da cidade baixa de Tóquio no Período Meiji. Além disso, em Narrativas de Genji, a dama Rokujô no Miyasundokoro encerra a questão amorosa com Hikaru Genji por ficar profundamente irritada com o incidente dos carros de boi e vai para Ise, de modo que esse conflito e o episódio da separação também são transplantados para o mundo das crianças que entram na puberdade.

(2) Como características de Comparando estaturas, podemos observar que as personagens pertencem à cidade baixa de Tóquio e que a protagonista está destinada a ser uma pessoa (cortesã ou prostituta) comprada com o dinheiro desse mesmo povo. 
(3) A protagonista é uma criança (menina) e as demais personagens principais ao seu redor também o são. A obra descreve o Período Meiji pelo ponto de vista das crianças que vivem no estrato mais baixo da sociedade e o quanto uma menina que pertence a essa classe e as demais crianças desse estrato são envolvidas no mundo dos adultos, no sistema e na profissão deles.

(4) Protagonista com sotaque da região de Kishû́.

- Nesse ponto observamos a vida de pessoas que não conseguiram continuar a viver no interior e acabam indo para Tóquio, trabalham e residem em casas de prostituição, e vendem suas filhas para serem cortesãs. No período Meiji em que o sistema de clãs é desfeito e as pessoas ganham mobilidade, o número de pessoas que iam para a cidade em busca de trabalho aumentou, e um dos exemplos típicos é descrito na obra. Nela não temos o protagonismo dos produtores, mas dos sem raízes que vivem nas cidades e vendem o seu trabalho assim como pais que vendem suas filhas para viver. Encontramos cidadãos do Estado que o eram só no nome, ou seja, cortesãs que jamais poderiam se tornar "cidadãs", ou então o futuro de moças sem nenhum direito como "cidadãs".

(5) Yoshiwara fazia parte do sistema reconhecido publicamente pelo Estado (continuou até próximo da derrota do Japão na Segunda Guerra Mundial)

- No sistema do Estado, ao se tornarem adultas, as crianças inserem-se mutuamente na relação de "comprar e ser comprado", e Midori que conhece por experiência própria o que isso significa, não tem outra alternativa a não ser se fechar dizendo que "não quer se tornar adulta". Sua resistência em "recusar a sociedade adulta" sequer é compreendida por sua mãe. Essa "sociedade adulta" não é outra coisa senão o próprio sistema do Estado. Aqui fica evidente a relação entre Estado X Indivíduo e Criança X Adulto. Isto é, na angústia de Midori aparece claramente o lado desumano do sistema do Estado para com a figura do indivíduo (principalmente da mulher), o qual alheio a sua vontade, ou a de seu pais como cúmplices, contrariando suas vontades, fazem uma oferenda de corpos para esse sistema mantido pelo Estado.

6 N. T.: A região de Kishû, também conhecida como Kiinokuni, abrange a totalidade da atual Província de Wakayama e a parte sul da Província de Mie. 
(6) Por outro lado, em Narrativas de Genji as cavernas da psicologia humana estão descritas de modo universal. Essa postura é utiliza na parte mais importante de Comparando as estaturas. Em termos concretos, temos a figura de Midori. Tendo seu orgulho ferido e sendo psicologicamente reprimida, sua descrição é feita de modo consciente a partir da cena em que Rokujô no Miyasundokoro, esposa do príncipe herdeiro e que foi ultrajada na Festa de Aoi, transforma-se em espírito vivo ameaçador. A ira de uma mulher da mais alta nobreza como Rokujô no Miyasundokoro é transferida para uma menina de um estrato no qual não lhe resta outra alternativa senão se tornar uma cortesã. Apesar das diferenças de época e de condição social retratadas, a obra capta a psicologia humana universal que é a dor de alguém que teve o seu orgulho ferido.

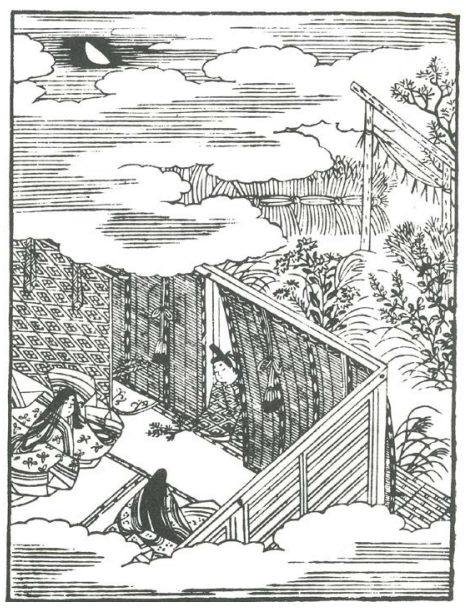

Figura D - Cena da despedida em Nowaki do capítulo Sakaki ${ }^{7}$

(7) Há, ainda, mais uma, a cena que descreve o final do amor adolescente de Midori e Shinjo enquanto uma cena marcante que tem Rokujô no Miyasundokoro em mente.

- a disputa por Genji e o lirismo do amor adolescente.

7 “Livro ilustrado Narrativas de Genji” - Volume Sakaki - cena da despedida de Nomiya. 『絵本源 氏物語』(賢木巻 - 野宮の別れの場面). Edição do Ano 3 da Era Shôô, acervo do Laboratório de Pesquisa de Literatura Nacional do Departamento de Letras da Universidade de Tokyo. 承応三年版 ・ 東京大学文学部国文学研究室蔵Associação de Publicação de Livros Raros, 1988. 
- Shinjo, ao deixar a cidade, faz chegar a Midori "uma flor artificial de narciso", mas por que essa flor? Porque toma por base o capítulo Sakaki de Narrativas de Genji. No capítulo em que Hikari Genji visita Rokujô no Miyasundokoro quando esta resolve ir para Ise seguindo a princesa Itsukinomiya, sua filha, ele lhe oferece um ramo de Sakaki. Sakaki é uma planta que mantém suas folhas verdes em qualquer época do ano, e com isso, pretendia transmitir-lhe uma mensagem, ou seja, que ela não "secasse" ou "não mudasse seu sentimento por ele".

Comparando estaturas, inspirada por esse episódio, deposita o sentimento imutável de Shinjo por Midori numa "flor artificial" de "narciso". O sentimento eterno, imutável, depositado numa flor artificial corresponde ao sentimento intenso de Hikaru Genji por Rokujô no Miyasundokoro (Kufukihara: 2008).

(8) Takekurabe descreve o funcionamento do Estado e as mudanças fiéis dos sentimentos humanos pelo ponto de vista de crianças de um estrato inferior da sociedade, mas o faz em consonância com o ponto de vista presente em Narrativas de Genji ou consciente do problema que ele representa. Independentemente da condição social superior ou inferior, a obra utiliza os temas que Narrativas de Genji desenvolvem: as relações humanas num sistema ou órgão comunitário imutável; o olhar de uma posição infinitamente inferior ou ainda, a relação entre Poder e Estado,

\section{Yosano Akiko - o apelo ao Estado por meio de um poema.}

(1)1904: Tu não precisas morrer - poema que contesta a guerra Russo-Japonesa. Mesmo ano em que ela começa a ministrar a Disciplina Narrativas de Genji.

(2) Midaregami (Cabelos revoltos) - Coletânea de poemas de Akiko e o poema antiguerra.

1901: publicado pela Associação Shinshi.

- Canta a liberdade sexual e a paixão que leva ao desejo carnal $\rightarrow$ resgate da natureza humana 


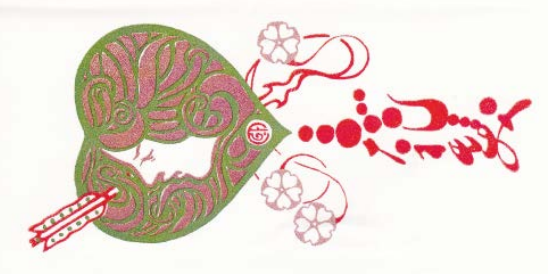

Figura E - Capa de Cabelos revoltos ${ }^{8}$

(elemento excluído pelo Governo Meiji que restaurou o poder ao Imperador).

- A partir de 1904, Akiko ministrou aulas sobre Narrativas de Genji por diversas vezes e inicia a primeira tradução da obra para a língua japonesa moderna. Os poemas antiguerra de Akiko afirmavam o sexo por amor, alinhando-se à tendência de Narrativas de Genji onde eram descritas várias formas de amar. No final do período Meiji, o Estado organizou-se sob o lema "país rico com forte poder militar" e quando o povo também se exultava pela guerra com os países estrangeiros, ela protesta contra a guerra promovida pelo Estado por meio de poemas que valorizam a "vida" dos indivíduos e de parentes, muito mais que a guerra promovida pelo Estado.

Nessa época, Suematsu Kenchô, por ordem do Premiê Itô Hirofumi, parte para a Europa com a função de divulgar a posição do Japão perante a guerra RussoJaponesa, durante dois anos.

Akiko proclama a importância da "vida" do povo em relação ao Imperador = Estado, e Suematsu trabalha para encaminhar a guerra do Estado para um lado vantajoso, o que é muito contrastante.

Enquanto Suematsu se empenha para o Estado na consecução da guerra, Akiko critica o Imperador que estimula a guerra (vide as partes grifadas do poema abaixo).

Como irmã mais velha que se preocupa com a vida do irmão mais novo, ela vai de um discurso extremamente humano e universal para um discurso que denuncia o Imperador.

8 Capa de Midaregami de Yosano Akiko na Coletânea Nova seleção de obras famosas reimpressas da Editora Kindai Bungakukan, 1974. 
Tu não precisas morrer

Ah, irmãozinho, choro por ti.

Tu não precisas morrer.

Sendo tu quem nascestes depois,

A tristeza de nossos pais é ainda maior, muito embora

Nosso pais o fizessem segurar o punhal

E ensinado a matar pessoas,

Dizendo para matar pessoas e morrer,

Depois de tê-lo criado até os vinte e quatro anos.

$[\ldots]$

$\underline{\text { Tu não precisas morrer }}$

$\underline{\mathrm{O} \text { imperador, à guerra }}$

Não vai pessoalmente.

Alheio, derrama o sangue de pessoas.

Dizer para que morram no caminho das bestas

Dizer que morrer é um orgulho.

Fosse vosso sentimento profundo,

Como poderíeis pensar isso desde o início?

$[\ldots]^{9}$

9 Vide poema na íntegra no Complemento 3. 


\section{Conclusão}

Observam-se características que saltam aos olhos diante de cada uma das publicações e empreendimentos ligados às Narrativas de Genji nas décadas de 1877 , 1887 e 1897. Na primeira, um jovem diplomata divulga internacionalmente a cultura japonesa à sociedade londrina; na segunda, as obras de Ichiyô revelam claramente que mesmo com o nascimento de um Estado Moderno, na sociedade base, meninas são vendidas para prostituição pelos próprios pais, sendo essa a realidade das crianças e dos adultos em torno a elas. Dessa obra é possível ler o questionamento sobre o que é o "Estado", o que é "povo", e onde esse "povo" está. Entrando na terceira, temos a vitória do governo Meiji na guerra contra a China e o avanço acelerado para ser um país rico e forte, mergulhando na guerra contra a Rússia como um grande empreendimento nacional. Por outro lado, Akiko, que na época inicia as aulas sobre Narrativas de Genji, compõe um poema opondo-se à guerra e direciona palavras críticas ao Imperador. A tensão é criada quando ela coloca o próprio irmão mais novo em contraposição ao Imperador na parte em que canta: "O imperador, à guerra, não vai pessoalmente". É impossível criar uma expressão assim sem a percepção de que tanto o imperador quanto um soldado são igualmente seres humanos. O espírito de Akiko em louvor ao ser humano surge como dura crítica em relação ao Estado e ao Imperador no momento em que a nação está em guerra.

Praticamente na mesma época, Suematsu Kenchô, o tradutor para o inglês de Narrativas de Genji, recebe a ordem do Primeiro Ministro Itô Hirofumi apelando aos países da Europa sobre com uma propaganda sobre a posição do Japão na Guerra RussoJaponesa. Tendo seu mérito reconhecido, ele se torna o Responsável pelo Conselho Privado e logo depois, membro da Teikoku Gakushi In, a Academia Imperial ${ }^{10}$. A atitude de Suematsu e de Akiko para com a Guerra Russo-Japonesa são contrastantes, mas a diferença está no modo como cada qual leu Narrativas de Genji. Suematsu divulgou ao mundo o grau de elevação da cultura japonesa, mas para Akiko, não se tratava de a obra ser elevada culturalmente para promover o poder nacional, a questão era que Narrativas de Genji apresentava pessoas dos mais diversos tipos, e que vivam com todas as suas como seres humano, saboreando alegrias, tristezas e sofrimentos e por vezes, adotando atitudes amorais. Presume-se que isso foi o que ela apreciou nos seres humanos ali retratados. E isso liga-se ao universo de Cabelos Revoltos que enaltecem a paixão e o sexo com amor.

Ichiyô, por sua vez, foi esplêndida em cantar sua juventude enaltecendo a si mesma. Enquanto descrevia a vida de cada uma das crianças, ela expõe a organização e as incongruências da nação e da sociedade, e principalmente em relação às meninas e às mulheres. Narrativas de Genji foi a obra que serviu de sustentáculo para o mundo de seu romance. Ichiyô não grita clamando por atenção. Limita-se tão somente a descrever

10 Instituição máxima do mundo acadêmico que objetiva o progresso tecnológico e científico. Nome recebido em 1906, como sucessora da antiga Academia de Tóquio (Tokyo Gakushikai In) criada em 1879. Em 1947, muda o nome para Academia do Japão (Nihon Gakushi In). 
realisticamente a situação, as ações e os sentimentos das personagens do romance. Contudo, nelas, a nação aparece espelhada tal como ela é. A tristeza do ser humano acorrentado ao sistema vigente transparece com nitidez a revelar belezas e possibilidade infinitas.

O mesmo ocorre com Narrativas de Genji. Descrevendo as alegrias e tristezas dos seres humanos, a obra reflete a situação da época e daquela sociedade. Ichiyô conseguiu herdar de maneira mais profunda a narratividade, o espírito e o lirismo de Genji Monogatari e construiu, no mundo do romance, o Estado e o sistema da época Meiji.

Ichiyô e Akiko trouxeram à tona a situação do Estado e suas contradições a partir da posição da mulher, do povo e do ser humano, ou, poder-se-ia dizer que as contestaram. Para elas, Narrativas de Genji não foi pura e simplesmente uma obra clássica refinada, mas serviu para enxergar a sociedade moderna como algo real, e também como esteio para nela sobreviverem. Aqui reside o poder oculto de um clássico, que existe para proporcionar deleite e aprendizado, e vai além: leva-nos a olhar para nós mesmos na vida que vivemos, e para enfrentar a sociedade, e creio que é isso que tanto Ichiyô quanto Akiko questionam e expõe.

\section{Referências Bibliográficas}

KAWAKATSU, Mari. Meiji kara shôwa ni okeru Genji Monogatari no hen'yô: kindai nihon no bunka sôzô [Transformações de Narrativas de Genji de Meiji a Shôwa: criação da cultura no Japão moderno]. Tokyo: Izumi Shoin, 2008.

KUFUKIHARA, Rei. Takekurabe - Suisen no tsukuribana no nazo o toku [Comparando estaturas - desvendando o mistério da flor artificial de narciso]. In: Genji monogatari no henbô - Towazugatari; Takekurabe; Genji shinsakunô no sekai. [Transformações de Narrativas de Genji - O mundo das obras "As confissões de Lady Nijô"; "Comparando estaturas" e "Novas peças de No de Genji”]. Tokyo: Ôfû, 2008, pp. 75-109.

SHINADA, Yoshikazu. Man'yôshû no hatsumei: kokumin kokka to bunkasôchi toshite no koten [Descoberta da Coletânea Miríade de Folhas: obra clássica como dispositivo cultural e estatal]. Tokyo: Shin'yôsha, 2001. 


\section{ANEXOS}

\section{Complemento 1: Sobre Takekurabe}

a Descreve o povo sem afinidade com o Governo e a política e a vida do povo da cidade baixa no início do período Meiji.

b As crianças na puberdade são o seu centro. As crianças são feitas protagonistas nos romances desde a formação da Literatura Infantil no período Taishô (1912-1925).

$\mathrm{c}$

As cinco crianças, cada qual em sua posição pueril, vivem sob o véu da profissão e da sociedade dos adultos, são miniaturas dos adultos = miniatura da vida do povo de Meiji.

d O eixo principal da narrativa é o amor adolescente de Midori e de Shinjo.

$\rightarrow$ o amor da infância segue a rota dos clássicos

- Narrativas de Ise, 23․ Episódio: "A mina d'água".

Narrativas de Genji aplicam a história das Narrativas de Ise no amor de infância do filho e da sobrinha de Hikaru Genji e de Yûgiri e Kumoigan dentro de uma narrativa longa.

Mil anos depois, Comparando estaturas faz renascer esses clássicos na forma de um romance.

Midori tem em mente a protagonista Wakamurasaki de Narrativas de Genji. (O romance registra como Wakamurasaki).

Midori, formosa, cheia de vida e sociável, torna-se outra pessoa, totalmente diferente, após o festival de verão; tranca-se em casa e toma atitudes histéricas e esse é o foco deste romance. Aqui, o sofrimento de "Rokujô no Miyasundokoro", esposa do ex Príncipe Herdeiro, é transferido para Midori, a cortesã do estrato mais inferior que pode ser vendida e comprada pelo dinheiro do povo. 
g formado monge, Shinjo jamais haverá de reencontrar com Midori que vira cortesã. Hikaru Genji transmite seu amor eterno por meio do ramo de sakaki que nunca seca e Shinjo faz o mesmo com a flor artificial de narciso.

*flor de narciso = desde o Período Edo era sinônimo de um jovem varão. $\mathrm{Na}$ mitologia grega também, Narciso é um garoto).

Complemento 2: Shinshi é uma das associações de poemas. Foi criada pelo poeta e tankaísta Yosano Tekkan (1873-1935) em 1899 com o objetivo de renovar o poema tanka. Em abril do ano seguinte, é lançada como revista Myôjô. Marcou época na história do tanka e do poema moderno de tendência romântica. Entre os membros, estavam Kitahara Hakushû (1885-1942), Kinoshita Mokutarô (1885-1945), Ishikawa Takuboku (1886-1912), entre outros.

Complemento 3: Yosano Akiko - Tu não precisas morrer

(Lamentando a viagem de Sôshichi, seu irmão mais novo para integrar as tropas de ataque)

Ah, irmãozinho, choro por ti.

Tu não precisas morrer.

Sendo tu quem nascestes depois

A tristeza de nossos pais é ainda maior, muito embora

Nossos pais o fizessem segurar o punhal

E ensinado a matar as pessoas

Dizendo para matar as pessoas e morrer

Depois de tê-lo criado até os vinte e quatro anos. 
As pessoas do outono da cidade de Sakai

Sendo um senhor que se orgulha da família antiga

Sendo tu que herdará o nome dos pais

Mesmo que o castelo desmorone

Mesmo que não desmorone, do que se trata,

Tu não sabes, das pessoas do outono

Família sem regras

Tu não precisas morrer

$\mathrm{O}$ imperador, à guerra

Não vai pessoalmente.

Alheio, derrama o sangue das pessoas,

Dizer para que morram no caminho das bestas

Dizer que morrer é um orgulho

Fosse vosso sentimento profundo,

Como poderíeis pensar nisso desde o início?

Ah, irmãozinho, na guerra

Tu não precisas morrer

No outono passado, ao nosso pai 
Atrasada, nossa mãe

Em meio à tristeza, condoída

Ofereceu seu próprio filho em proteção à casa,

Nessa Vossa Era Imperial que haveria de ser de paz

Os cabelos de mamãe são mais grisalhos agora

Chora à sombra da cortina

Frágil, a jovem esposa

Tu esqueces, lembreis,

Separou-se sem ficar dez meses,

Pense no seu sentimento de menina

Tu não és sozinho neste mundo

Ah, a quem recorrer,

Tu não precisas morrer.

Obs: O presente texto foi extraído de Obras completas de Yosano Akiko. Volume IX. (Poemas diversos capítulo 40), Tokyo: Kodansha, 1980.

(Tradução do japonês para o português de Neide Hissae Nagae) 